\title{
Research on Poverty Reduction Effect of Rural Microcredit Based on FGT Index
}

\author{
Shouying Ying \\ Chengdu University of Information Engineering \\ Chengdu, China 610103
}

\author{
Qiaoxi Fan \\ Chengdu University of Information Engineering \\ Chengdu, China 610103
}

\begin{abstract}
As one of the important means of poverty alleviation work in China, how the actual poverty reduction effect of rural microfinance is worth studying. Taking Sichuan Province as an example, based on the time series data from 1994 to 2014, this paper constructed FGT index, used vector autoregressive model, impulse response and variance decomposition method to quantitatively study the poverty reduction effect of rural microfinance. The results show that: The breadth of poverty, the depth of poverty and the intensity of poverty in the rural areas of Sichuan all have a tendency to expand. The effect of reducing poverty in rural microfinance is small and decreasing; reducing poverty is better than reducing inequality between the number of people living in poverty and income distribution.
\end{abstract}

Keywords-FGT index; rural microfinance; poverty

\section{INTRODUCTION}

Microfinance, originated in Bangladesh and Indonesia, provides unsecured and unsecured microcredit services to low-income and poor people. Since 1990s, our country draws lessons from the experience of reducing the poverty of foreign microcredit, and in rural areas, the poverty alleviation type micro credit service is developed, and the rural low-income people and the poor people are provided with unsecured and unsecured micro credit services. Wu Guobao (2003) believes that the development of microfinance has a direct effect on the sustainable improvement of the poor's access to effective sources of finance, and indirectly improves the poor's access to other property income, as well as their viability and development opportunities. [1]

After years of development, through qualitative and quantitative research, many scholars believe that rural microcredit can effectively alleviate rural poverty. In foreign research, such as Robinson and Marguerite(2001) consider that microfinance has a significant effect improving household life and business operation, thus it to reduce the incidence of poverty in the region.[2] Based on the analysis of OLS model, KS Imai et al. (2012) considers that the scale of micro-credit has a positive effect on household income in develop area.[3]In China, Zhang Lijun, Zhan yong (2006) found that micro-credit has significant counter-lock support effect in industrial, structural and technical locking, which is beneficial to increase farmers' income. [4]Zhu Ganyu, Dong Xuejun (2007) used quantitative analysis method to study the minority areas and the result shows that there is obvious positive effects of micro-credit on the increasing the farmers' income, especially micro-credit have better performance in non-agricultural industries.[5]Domestic and foreign studies have studied the effect of microcredit on poverty reduction from different perspectives. However, previous studies have mostly focused on the per capita net income, and have only discussed the incidence of poverty on the surface. There are few studies on the internal differences and income distribution of the poor groups. Amartya Sen believes that an ideal poverty index should have three dimensions, the breadth, depth and intensity of poverty. It is not only to reflect the proportion of the poor, but also to reflect the poverty level of the poor, and to be sensitive to the distribution of the income among the poor. In addition, with economic and social development, people pay more attention to the problem of relative poverty, if the absolute poverty line is used to measure the level of poverty, it will lead to the equalization of low-income groups. The use of the absolute poverty line as a measure in the past is not applicable. The difference of regional consumption level also requires that the problem of poverty should be studied by region. Based on this, this paper taking Sichuan Province as an example, using relative income as the poverty line, and according to the research of the international economic cooperation organization, the standard is $50 \%$ of the median of the comparable income in the current period. Therefore, according to the FGT index, this paper constructs the poverty breadth, depth and intensity index to reflect the real level of poverty in a comprehensive way.

\section{ANALYSIS OF DATA CHARACTERISTICS}

\section{A. Data Sources}

In Sichuan, the poverty area is wide, the quantity is large, the degree is deep, and the scale of the poor population ranks 6 th in the whole country, the regional overall poverty is prominent. The poverty alleviation office of the State Council regards Sichuan as the focal point, therefore, this article selects Sichuan as the research area. Since 1994, rural micro-credit has been established and served for rural economic development and poverty alleviation. Therefore, this paper selects the data from 1994-2014 as the research sample. The data are mainly from China Statistical Yearbook, Sichuan Statistical Yearbook, Sichuan Rural Statistical Yearbook, China Agriculture Yearbook, Almanac of China's 
Finance and Banking and Poverty Monitoring Report of rural China. As the statistical yearbook does not provide disaggregated data on rural per capita net income for the period 1994-2002, this article refers to the practice of Hou Shi'an and Xie Ling, taking the rural per capita net income from 1994 to 2002 as the median income level of the rural population of $20 \%$ of the grouped data, and referring to the proportion of differences between the average growth rate and the five groups of data in the urban population grouping data. Based on the data of 2003, the group data of Rural residents per capital net income from 1994 to 2002 were introduced.[6] The data processing is completed by POVCAL and EVIEWS7.0 analysis software.

\section{B. Data Feature Analysis}

The traditional poverty measurement index is mainly poverty population index and poverty distance index, which cannot reflect the relative poverty and the inequality of income distribution. In 1976, Amartya Sen constructed an axiomatic approach, proposing the sen index to measure the changes in income among the poor and the changes in poverty caused by income transfers between the poor and between the poor and the rich. [7] In 1984, Foster, Greer and Thorbecke further raised the FGT index based on Sen index, reflecting not only the incidence and poverty level of the poor, but also the sensitivity of income distribution. The concrete forms are as follows:

$$
\mathrm{FGT}(\alpha)=\frac{1}{\mathrm{~N}} \sum_{\mathrm{i}=1}^{\mathrm{q}}\left[\frac{\mathrm{Z}-\mathrm{Y}_{\mathrm{i}}}{\mathrm{Z}}\right]^{\alpha}
$$

Among them, $\mathrm{N}$ is the total population, $\mathrm{q}$ is the number of people living in poverty, $\mathrm{Z}$ is the poverty line, $\mathrm{Y}_{\mathrm{i}}$ the per capita net income of the poor. $\alpha$ is the coefficient of aversion to poverty, which reflects the sensitivity to the depth and intensity of poverty. When $\alpha=0, \mathrm{FGT}(0)$ is the incidence of poor population, that is the breadth of poverty, which is expressed in $\mathrm{H}$; When $\alpha=1, \mathrm{FGT}(1)$ is the poverty gap index, that is the depth of poverty, which is expressed in PG, reflecting the gap between the poor and the poverty line; when $\alpha=2, \mathrm{FGT}(2)$ is the squared poverty gap index, or poverty intensity, which is expressed in SPG, reflecting the inequality of the income distribution of the poor.

In order to observe the poverty situation of Sichuan province effectively, the FGT index is calculated by the POVCAL software of the World Bank, and the change of poverty is intuitively reflected by the sequence diagram. The result is shown in "Fig. 1".

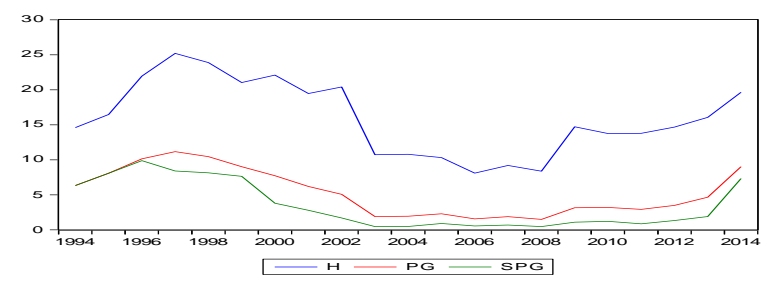

Fig. 1. The breadth of poverty $(\mathrm{H})$ 、 the depth of poverty(PG) and the strength of poverty(SPG).
From "Fig. 1", we can see that the FGT measured by the relative poverty line decreases first and then rises, showing an obvious trend of expansion. From 1994 to 1996, FGT poverty index continued to rise, the poverty incidence stage has been maintained at above $15 \%$ higher level, poverty gap rate and squared poverty gap above 5\%; from 1997 to 2002, the government carried out large-scale poverty alleviation work, rural poverty has been greatly improved, the FGT index fluctuating dropped. This stage, the poverty population index has decreased from $25 \%$ to $10 \%$, and the depth of poverty(PG) and the strength of poverty(SPG) have decreased to below 5\%.; from 2003 to 2007, the FGT index is relatively stable, maintained at a low level; from 2008 to 2014, the FGT index rose slowly, this stage is affected by the economic environment, the incidence of poverty index exceeded the level of $15 \%$, from the beginning of 2013 the poverty gap and squared poverty gap rate more than $5 \%$, increased significantly. This shows that after 20 years of development, the per capita net income of rural residents in Sichuan is lower than the average level of the people are still more. The relative poverty line is rising with rural residents' per capita consumption, but the income levels of low-income groups are unable to catch up with rising poverty standards. Rural internal income gap expanding trend is obvious, for the poor and the rich, the poor and the poor expansion of the income gap. In general, the poverty in rural areas in Sichuan is deepening in breadth, depth and intensity.

\section{EMPIRICAL ANALYSIS}

\section{A. Selection of Indicators}

Rural micro-credit alleviates rural poverty through direct mechanism and indirect mechanism, which is manifested in providing loans to poor farmers directly to improve their lives; secondly, providing financial services to promote rural economic development. The "trickle-down effect" benefits the poor. [8] Fiscal support for agriculture is also an important way to alleviate poverty. Based on the above analysis, this paper selects six variables: rural microfinance (credit), rural economic development level (RGDP), fiscal support level (FSC), and the breadth (H), depth (PG) and intensity (SPG) of poverty. Referring to Zhang Lijun, Zhanyong's method, the amount of rural microcredit is measured by the loan amount of rural credit cooperatives. The level of rural economic development is measured by the gross output value of farming, forestry, animal husbandry and fishery. The level of fiscal support for agriculture is expressed by the proportion of fiscal expenditure to total expenditure. The breadth, depth and intensity of poverty are measured by the FGT index. The poverty line is based on the rural relative income poverty line, which is the median of the current comparable income is $50 \%$. In order to eliminate the influence of price, the rural micro credit amount and the total output value of agriculture, forestry, animal husbandry and fishery were converted to the 1994 comparable price. In order to eliminate the influence of heteroscedasticity, the logarithm was taken for standardization treatment and the variables were lncredit, $\operatorname{lng}$ rdp, $\operatorname{lnfsc}, \ln \mathrm{H}$, lnpg and $\operatorname{lnspg}$. 


\section{B. Model Construction}

The goal of poverty alleviation is not only to reduce the number of people living in poverty in order to achieve poverty eradication, but also to narrow the income gap in order to achieve equality in income distribution. Based on the above analysis, this paper constructs the following model:

$$
\begin{aligned}
& F_{t}(H)=\alpha F_{t-j}+\beta Y_{i_{i} t-j}+\mu_{i_{i} t} . \\
& F_{t}(P G)=\alpha F_{t-j}+\beta Y_{i, t-j}+\mu_{i, j} . \\
& F_{t}(S P G)=\alpha F_{t-j}+\beta Y_{i_{i} t-j}+\mu_{i_{i} t} .
\end{aligned}
$$

In the formula, $\mathrm{F}_{\mathrm{t}}$ is the poverty width $(\mathrm{H})$, the depth $(\mathrm{PG})$ and the intensity (SPG) at different time points; $\alpha, \beta$ is the coefficient; $\mathrm{Y}_{\mathrm{i}, \mathrm{t}-\mathrm{j}}$ is the amount of rural microcredit, the level of rural economic development, and the level of financial support for agriculture at different lag points, $\mu_{i t}$ is the random error term. For easy analysis, the following three models' explained variable are H、 PG、SPG respectively, this paper refers to Model 1, Model 2 and Model 3.

1) Unit root test and cointegration test: When nonstationary time series are estimated directly by OLS, pseudo-regression problem will be caused. Therefore, in this paper, the unit root test of time series data is carried out by Eviews7.0. The commonly used methods of unit root test are DF test and ADF test. In this paper, ADF method is used to test the unit root of variables, and the results are shown in "Table I".

TABLE I. ADF UNIT RoOT TEST

\begin{tabular}{l|l|l|l|l}
\hline \multicolumn{1}{c|}{ Variable } & ADF test & $\begin{array}{c}\mathbf{5 \%} \text { critical } \\
\text { value }\end{array}$ & P value & Stationarity \\
\hline $\begin{array}{l}\text { LNCREDI } \\
\mathrm{T}\end{array}$ & -4.198528 & -3.658446 & 0.0180 & Stationary \\
\hline $\begin{array}{l}\mathrm{D}(\mathrm{LNCRE} \\
\mathrm{DIT})\end{array}$ & -6.000287 & -3.673616 & 0.0006 & Stationary \\
\hline LNRGDP & -2.960353 & -3.710482 & 0.1702 & $\begin{array}{l}\text { Non- } \\
\text { Stationary }\end{array}$ \\
\hline $\begin{array}{l}\mathrm{D}(\mathrm{LNRGD} \\
\mathrm{P})\end{array}$ & -4.151836 & -3.690814 & 0.0217 & Stationary \\
\hline LNFSC & -3.682566 & -3.658446 & 0.0478 & Stationary \\
\hline $\mathrm{D}(\mathrm{LNFSC})$ & -5.749176 & -3.673616 & 0.0010 & Stationary \\
\hline LNH & -1.293978 & -3.658446 & 0.8595 & $\begin{array}{l}\text { Non- } \\
\text { Stationary }\end{array}$ \\
\hline D(LNH) & -4.339836 & -3.673616 & 0.0145 & Stationary \\
\hline LNPG & -0.215065 & -3.658446 & 0.9875 & $\begin{array}{l}\text { Non- } \\
\text { Stationary }\end{array}$ \\
\hline D(LNPG) & -3.728292 & -3.673616 & 0.0453 & Stationary \\
\hline LNSPG & 0.241628 & -3.658446 & 0.9965 & $\begin{array}{l}\text { Non- } \\
\text { Stationary }\end{array}$ \\
\hline D(LNSPG) & -3.548221 & -3.673616 & 0.0626 & Stationary \\
\hline
\end{tabular}

The test results show that LNCREDIT and LNFSC are zero order monolithic stationary sequences and LNRGDPN LNFSCN LNHN LNPG and LNSPG are non-stationary sequences at the significant level of $5 \%$, but after the first order difference, all variables are first-order single-integer sequences, which indicates that there may be a long-term equilibrium relationship between sequences, which can be further examined.

There are two kinds of cointegration test methods: EG two-step method and Johansen maximum likelihood method. Johansen cointegration test is used in this paper. The results show that there are at least three long-term equilibrium relationships in the time series data at the significant level of $5 \%$.VAR models were established respectively by using DLNHN DLNPGG DLNSPG as interpreted variables and DLNCREDITD DLRGDPN DLNFSC as explanatory variables.

TABLE II. JOHANSEN CO-INTEGRATION TEST

\begin{tabular}{l|l|l|l|l}
\hline $\begin{array}{l}\text { Hypothesized } \\
\text { No. Of CE(s) }\end{array}$ & Eigenvalue & $\begin{array}{l}\text { Trace } \\
\text { Statistic }\end{array}$ & $\begin{array}{l}0.05 \\
\text { Critical } \\
\text { Value }\end{array}$ & Prob \\
\hline None* & 0.998127 & 182.0249 & 83.93712 & 0.0000 \\
\hline At most $1^{*}$ & 0.711252 & 68.97772 & 60.06141 & 0.0073 \\
\hline At most 2* & 0.673563 & 46.61813 & 40.17493 & 0.0099 \\
\hline At most 3* & 0.587634 & 26.46678 & 24.27596 & 0.0261 \\
\hline
\end{tabular}

2) VAR model construction: The VAR model is mainly used to predict and analyze the dynamic impact of random perturbation on the system, including the magnitude of the impact, positive and negative, and duration.

First, select the lag of the model. The lags of different VAR models are determined according to the maximum likelihood value, SIC and AIC value, and the stability of the model is verified by AR root graph to ensure the validity of the analysis results. The results show that the optimum lag of co-integration equation of model 1 is 2 , and the results of AR root detection show that all roots are in unit circle and the model meets the requirements of robustness. Both models 2 and 3 have an optimal lag of 1, the results of unit root graph show that all roots are in the unit circle, which indicates that the model is robust.

Inverse Roots of AR Characteristic Polynomial

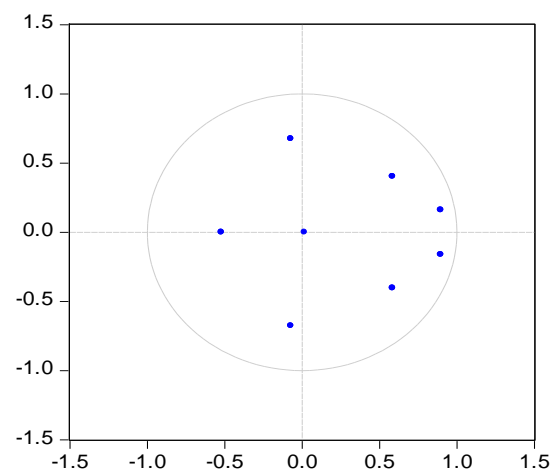

Fig. 2. AR root map of Poverty width(H) 


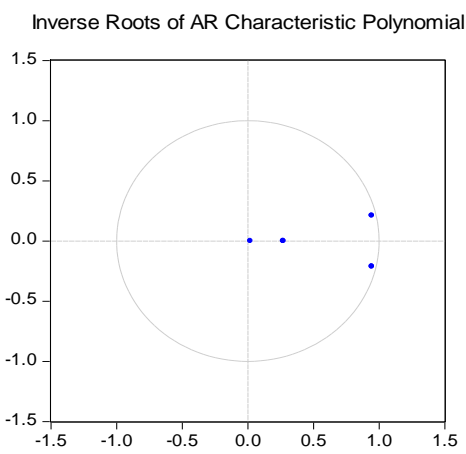

Fig. 3. AR root map of poverty depth(PG).

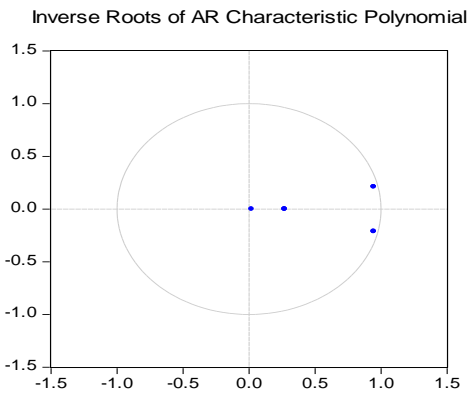

Fig. 4. AR root map of poverty intensity (SPG).

3) Impulse response analysis: The impulse response function can vividly depict the impact of a standard deviation of the random perturbation term on the current and future values of the endogenous variables. The effect of rural microfinance on poverty reduction is the focus of this paper. Therefore, the impulse response function is used to analyze the impact of rural microfinance on poverty index in Sichuan province. The following three indexes of FGT are selected to analyze the impact of rural microfinance. The results are shown in "Fig. 5", "Fig. 6" and "Fig. 7".

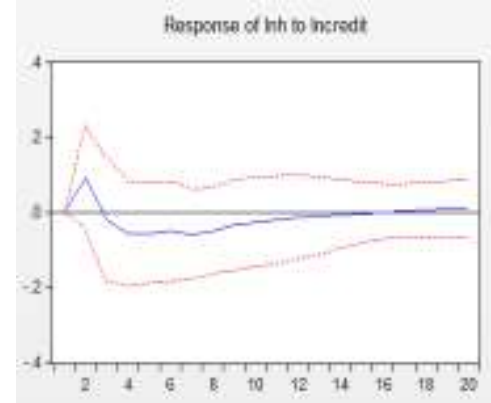

Fig. 5. Impulse response of poverty width $(\mathrm{H})$.

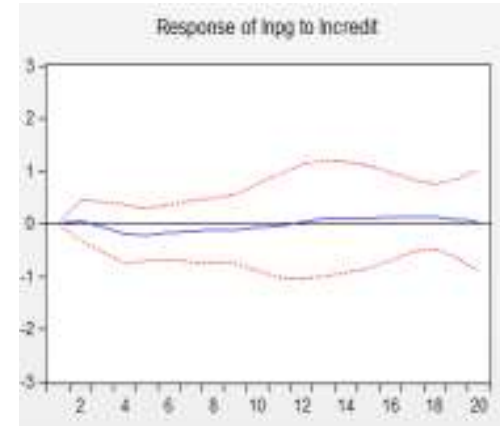

Fig. 6. Impulse response of poverty depth (PG).

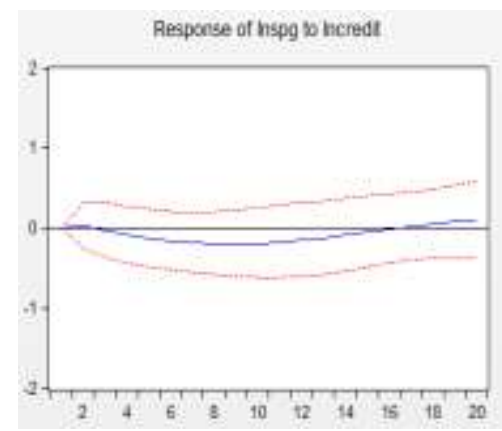

Fig. 7. Impulse response of poverty intensity (SPG).

From the figure above, the rural microfinance has a sustained and small positive impact on the poverty index. "Fig. 5" shows that the overall impact of rural microfinance on poverty breadth is not significant. In the first three periods, the positive effect of rural microcredit on reducing the number of poor declined after reaching its peak in the second period. From the 3 rd to 14 th period, the rural micro-credit has a long negative effect on the poverty index. After the 14 th period, the incidence of poverty response to the rural micro-credit impact is stable, sustained in the zero region. This indicates that the development of rural micro-credit can effectively solve the problems of restricting the flow of funds in rural areas, and drive the majority of rural residents to increase their income. However, with the rising consumption level of rural residents driving the poverty line upward, lowincome groups may return to poverty; In addition, the renewal and upgrading of rural microcredit management mechanisms have not kept pace with their scale expansion, resulting in problems such as the upward shift of poverty alleviation objectives, prime rate grabbing by privileged classes, and financial fluctuations that offset the effects of poverty reduction and so on, Problems such as poverty alleviation target upward, privileged class grabbing preferential interest rate, financial fluctuation counteracting the effect of poverty reduction and so on, make the rich get richer and richer, the poor come poorer, the scale of the poor population expands. With the development of the rural micro-credit management mechanism, the negative impact on poverty breadth gradually weakened, but it did not show a significant positive effect.

"Fig. 6" shows that rural microcredit has a sustained but small positive effect on the depth of poverty. Before 10 periods, rural microfinance has a negative impact on the 
poverty gap rate; after 10 periods, it shows a sustained and small positive impact. From "Fig. 7", it can be seen that the development of rural microfinance has a negative effect on the impact of square poverty distance. There was a long negative effect before the 17th period, a short positive effect after the 17 th stage, there was a slight caudal phenomenon. On the supply side, there is a problem of "poverty targeting" in rural microcredit, where loans are "poverty-neutral." [9] prospective borrowers are mainly poor families with poor economic conditions and ability of paying back loans. They exclude extreme poverty and lack enough protection for vulnerable groups. The poverty alleviation effect of the middle poverty groups is obvious. [10]. On the demand side, because of the uncertainty of agricultural production, farmers refuse loans because they are worried that they cannot repay their loans, and poor farmers do not show obvious borrowing behavior, and poverty alleviation funds are "captured" by non-poor groups.

Poor farmers did not show obvious borrowing behavior, and anti-poverty funds were "captured" by non-poor groups. In addition, the lack of a private credit system further exacerbates the role of pro-poor loans, and people misinterpret microcredit as relief money, with the phenomenon of non-payment, waiting for it, relying on it, asking for it and so on, [11] resulting in an increase in the proportion of non-performing loans in rural micro-credit and the suppression of the effect of poverty reduction. On the whole, rural microfinance plays a minor role in reducing the income gap and alleviating the problem of income inequality. The expansion of microfinance scale may exacerbate the rural income gap.

4) Variance decomposition: In order to describe the influence of variables on poverty reduction clearly, this paper uses variance decomposition to obtain the impact ratio of different innovation in different equations. From the table below, we can see that the changes of three indicators of poverty are more affected by themselves. On the whole, the contribution of rural microcredit to the poverty index is relatively small, accounting for only between $7 \%$ and $18 \%$, and the contribution rate of rural microfinance to the depth of poverty is higher than that of poverty breadth and intensity. From "Table III", from the 10th to the 20th forecasting period, the impact of rural microfinance and fiscal support for agriculture on the incidence of poverty is decreasing. It shows that both have a pull effect on poverty reduction, but the key is whether it is sustainable. Economic backwardness, the poor lack investment demand small demand for credit and poor infrastructure conditions in poor areas, these results in uneven coverage of rural banks network, thus regional development is extremely uneven. Studies have shown that past anti-poverty policies have also failed to increase the income and consumption of poor farmers, while the income and consumption of relatively wealthy farmers have increased substantially, [12] this have exacerbated the income gap among residents. As a result, the overall impact of rural microcredit on poverty reduction is limited. In addition, "Table III" shows that rural economic development has a positive impact on poverty reduction and an increasing trend. It indicates that economic growth has absorbed and benefited more grass-roots people in society and expanded employment opportunities and capacities of poor groups. This economic growth is pro-poor.

TABLE III. VARIANCE DECOMPOSITION OF EACH VARIABLE TO LNH

\begin{tabular}{c|c|c}
\hline Variable & LNH & LNH \\
\hline Period & 10 & 20 \\
\hline S.E. & 0.47244 & 0.51326 \\
\hline LNH & 77.41975 & 78.09944 \\
\hline LNCREDIT & 11.88238 & 10.49406 \\
\hline LNRGDP & 4.38284 & 5.78659 \\
\hline LNFSC & 6.31503 & 5.61991 \\
\hline
\end{tabular}

"Table IV" and "Table V" show the variance decomposition of each variable to the depth and intensity of poverty. The positive impact effect of rural microfinance and rural economic development on poverty gap and square poverty distance is decreasing, but for the poor distance, the contribution rate of rural microfinance is relatively high; for the square poverty distance, the contribution rate of the rural economic development is higher. Some studies have shown that, compared to agricultural investment, microcredit has a significant effect on non-agricultural investment. [13] With the uncertainty of agricultural production, rural microcredit is more likely to lend to non-agricultural industries or to moderately poor groups with the ability to repay loans. Therefore, on the one hand, the rural microcredit reduces the gap between the middle poor and the poverty line, on the other hand, it also results in the widening of the income gap between the extremely poor and the middle poor. In addition, the "trickle-down effect" of rural economic growth has not been played out, and the dividends of economic growth have been cut off by the rich, not passed on to the poor, especially the extremely poor, and inequality in income distribution is evident. From "Table V", the fiscal public expenditure for rural development can effectively alleviate the problem of income distribution in rural areas, the contribution of fiscal support for agriculture to narrow poverty gap and income distribution is increasing from 10 to 20 periods.

TABLE IV. VARIANCE DECOMPOSITION OF EACH VARIABLE TO LNPG

\begin{tabular}{|c|c|c|}
\hline Variable & LNPG & LNPG \\
\hline Period & 10 & 20 \\
\hline S.E. & 1.035393 & 1.297524 \\
\hline LNPG & 79.34561 & 80.45118 \\
\hline LNCREDIT & 18.32843 & 17.10468 \\
\hline LNRGDP & 0.980565 & 0.851099 \\
\hline LNFSC & 1.345392 & 1.593039 \\
\hline
\end{tabular}

TABLE V. VARIANCE DECOMPOSITION OF EACH VARIABLE TO LNSPG

\begin{tabular}{|c|c|c|}
\hline Variable & LNSPG & LNSPG \\
\hline Period & 10 & 20 \\
\hline S.E. & 1.680305 & 2.100679 \\
\hline LNSPG & 76.5678 & 76.84997 \\
\hline LNCREDIT & 7.250338 & 6.909503 \\
\hline LNRGDP & 13.29274 & 11.10318 \\
\hline LNFSC & 2.889126 & 5.137342 \\
\hline
\end{tabular}




\section{CONCLUSION}

By constructing a vector autoregressive model of FGT index (poverty breadth, depth and intensity), rural microcredit, rural economic development level, and financial support for agriculture, this paper tests the co-integration relationship between variables. The dynamic response relationship between rural microfinance and poverty index is analyzed by generalized impulse response and variance decomposition, and the following conclusions are obtained: (1) the extent, depth and intensity of rural poverty in Sichuan Province are all increasing. (2) The effect of rural microcredit on poverty reduction is relatively small and not sustainable, and reducing the degree of poverty is better than reducing the inequality of the number of poor people and the distribution of income, that is lack of pro-poor. (3) The "trickle-down effect" of rural economic development has a limited effect on the poor and is better in reducing absolute poverty than in relative poverty. (4) The effect of financial support for agriculture on reducing the income gap within poverty is gradually apparent. The reason is that the rural microfinance institutions in Sichuan are influenced by the economic environment and the infrastructure, but the institutions are concentrated in the urban areas, the financial points in the poor areas are obviously insufficient, meanwhile, the poor people lack of investment demand, which leads to the "low level equilibrium trap" of economy and finance in poor areas, it greatly reduces its effect on poverty reduction. On the other hand, the objective of microfinance institutions is to maintain poverty alleviation while maintaining financial sustainability. However, due to the imperfection of the private credit system, there are problems such as "information asymmetry" and "moral hazard" in lending activities. This has led to a large number of non-performing loans in rural microcredit, worsening the operating conditions of institutions, and shrinking the rural financial system as a whole, which has further restrained the poverty reduction effect of rural microcredit. In addition, there is a problem of "poverty aiming" migration in rural microfinance. The investigations show that aid-targets of rural microfinance are mainly based on the poor households questionnaire published by the government, and the formalism of the government on the issue of precise alleviate poverty is serious, especially in the identification of the poor households, which results in the deviation of poverty identification. As a result, the impact of rural microcredit on poverty reduction is limited.

Based on the above analysis, this paper puts forward the following suggestions: first, to improve the rural micro-credit institutions, solve the poverty targeting problem, and ensure the goal of poverty alleviation is accurate. Second is to improve the private credit system, and build a mutual supervision of the loan model. Meanwhile, it is to solve the problem of "adverse selection" and "moral hazard" and monitor the use of loan funds by farmers. Third, to create a good market environment, stimulate the investment and production demand of farmers. And then it will be increased the demands for credit to realize the balance of supply and demand, in order to improve the income of farmers to increase their income and poverty. Fifth, to improve the construction of rural infrastructure, provide hardware support for rural financial poverty alleviation and industrial development, rationally set up rural financial outlets. Sixth, to implement precise poverty alleviation policy, strengthen the poverty identification problem, dynamic tracking of poverty and poverty.

\section{REFERENCES}

[1] Wu Guobao, Li Xingping. The contribution of microcredit to poverty alleviation and development in China $[\mathrm{J}]$. Finance and Economics,2003(11):7-10.

[2] Robinson,Marguerite.The microfinance revolution:sustainable finance for the poor[M].Washington D.C.:The World Bank and Open Society Institute,2001.

[3] Katsushi S. Imai, Raghav Gaiha, Ganesh Thapa, Samuel Kobina Annim. Microfinance and poverty -a macro perspective[J].World Development,2012,40(8):1675-1689.

[4] Zhang Lijun, Zhanyong. Financial development and poverty reduction-analysis on microfinance 1994-2004 in China [J]. Modern Economic Science,2006(6):36-42.

[5] Zhu Ganyu, Dong Xuejun. Empirical study of performance of rcc's microfinance in poor ethnic areas-taking Enshi autonomous prefecture of Tujia \& Miao nationalities, Hubei province as the example [J]. Journal of South-Central University for Nationalities(Humanities and Social Sciences),2007(1):56-60.

[6] Hou Shi'an, Xie Ling. Analysis on the degree of rural poverty and its influencing factors in Guizhou Countryside: a Multidimensional measure based on the Poverty Index of Guizhou Rural FGT from 2001 to 2012 [J]. Guizhou Social Sciences,2014(7):123-124

[7] Ma Xinwen. A review of amartya sen's theory and methods of right poverty [J]. Social Sciences Abroad,2008(2):71-72.

[8] Hu Zongyi, Luo Liudan. The utility research of micro credit in reduction of rural poverty based on panel model $[\mathrm{J}]$. The Theory and Practice of Finance and Economics,2016(3): 11-14.

[9] Lin Wanlong, Yang Cong from. Can poor farmers make effective use of poverty alleviation microfinance services? - A case study of mutual assistance fund for poor villages in Yilong County, Sichuan Province [J]. Chinese Rural Economy,2012(2):35-45.

[10] Katsushi S. Imai,MD. Shafiul Azam. Does microfinance reduce poverty in bangladesh? new evidence from household panel data[J]. The Journal of Development Studies, 2012,48(5): 633-653.

[11] Xie Yumei, Xu Wei, Cheng Enjiang, Zhang Guo. Comparative research on microfinance innovation model based on precision poverty alleviation perspective $[\mathrm{J}]$. China Agricultural University Journal of Social Sciences Edition,2016(5):54-55.

[12] Park,Albert and Wang, Sangui: Community-based development and poverty alleviation: an evaluation of china's poor village investment program[J], Journal of Public Economics, 2010(9):790-799.

[13] Tang Wenhao. A study on the poverty alleviation of rural microcredit based on the perspective of poor farmers [D]. Jiangsu: Nanjing Agricultural University,2011. 